\title{
Improvement of Overvoltages of PWM Inverter Fed Induction Motor Drives
}

\author{
${ }^{1}$ Raghu Ram.V, ${ }^{2}$ Dr.V.Kama Raju, ${ }^{3}$ Dr.G.S. Durga Prasad \\ ${ }^{I}$ Research Scholar, JNTUH, \\ ${ }^{2}$ Professor of EEE - MITS, Hyderabad \\ ${ }^{3}$ Professor \& Principal of KITS - Khammam \\ 1'ram.vasireddy@yahoo.com
}

\begin{abstract}
The method of induction motor drives fed by converters are essentially accompanied by highfrequency interferences which are caused mainly by freeloading currents of the common and differential modes. The discharged current propagates through the transmission cable and signal cables with understanding the problem of overvoltage in inverter fed induction motor with long supply cables . Considering classical transmission line analysis, and traveling-wave analysis with zero initial charges on cables, these transient over voltages are about twice the dc link voltage with a short rise time of about $200 \mathrm{~ns}$. Nevertheless for long cables, these transient overvoltages may reach 3 or 4 p.u. Hence some of the improvement methods need to be implemented for long cable which are fed to the adjustable speed drives with PWM technique due to the transients. Due to the high frequency interference there are many problems will accurs at the different stages This paper proposes that the transient overvoltages on ac induction motors when connected through a cable of arbitrary length to IGBT-PWM inverters. Modeling of the Induction motor and the when the high frequency is applied and also it needs to calculate the overvoltage in the inverter fed induction motors through the long cabels. The cable characteristics and performance of the induction motor can be implemented using the MATLAB / Simulink which is convenient to analyze the proposed method.

Kew words: Inverter fed Induction motor drives, cabel length, voltage reflection, gauge of the cable.Narrow PWM pulse.
\end{abstract}

\section{Introduction}

The perfect induction motors are designed to work with fixed sinusoidal frequency, which are being used with variable frequency drives in an increasing manner. An application of AC induction motors fed by pulse width modulated (PWM) drives continues at the rate of about 2, 50,000 per year. The waveform of the output voltage of PWM inverter is not a sine wave, but a series of square wave pulses to produce a reasonable accuracy of sinusoidal wave. Although there is a long history of successful use of standard motors in this type of waveform, the possible effects on the motor insulation must be carefully considered. One of the remarkable advances in power switching devices has been increased switching speeds and switching frequencies related in addition to the high frequency operation associated PWM AC units. This will result in a current waveform of sinusoidal motor with less ripples, fewer copper losses, and less switching loss. However, the high increasing rate of voltage, $\mathrm{dv} / \mathrm{dt}$, has adverse effects on motor insulation systems and helps to withstand the current problems.

Application of advanced semiconductor elements in the modern voltage inverters allows substantial reuse of their switching frequency. Consequently, the delivered trapezoidal voltage pulses reach considerably high values of $\mathrm{dv} / \mathrm{dt}$ (often more than $10 \mathrm{kv} / \mu \mathrm{s}$ ). Situated in a system consisting of the PWM inverter, feeding cable and induction motor (IM) is then strongly influenced by its leakage capacitances and characterized by circulation of the high-frequency parasitic common and differential mode currents. These currents may produce, beside various over voltages and growth of additional sizes in the motor and inverter, electromagnetic interferences (EMI) propagated into the surroundings as conducted and radiated emissions. These interference signals are (by the corresponding standards) divided into two groups: those produced by harmonics up to $9 \mathrm{kHz}$ and those generated by very fast changes of voltage in the semiconductor devices (in the intervals $9-150 \mathrm{kHz}$ and $150 \mathrm{kHz}-30 \mathrm{MHz}$, respectively). The electromagnetic interference can adversely affect the operation of telecommunication and signal cables which are in parallel with the power supply cable and other low current devices. The analysis of the phenomena is extremely difficult and requires correct mathematical models of all parts of the system. This includes a good representation of distributed parameter both induction motor and power cord and a sufficiently sophisticated model of the inverter. Currently, there are several approaches that allows the highest quality separated element modeling system [1]. Overvoltage problems with long cable drives due to the steep rise time of the pulse voltage has become an important area of research in the past decade. The phenomenon of overvoltage is described here is, normally using the traveling wave, and phenomena of 
reflection: a voltage pulse, which began in the inverter, which is reflected in the motor terminals due to a mismatch between the characteristic impedance and the impedance of engine inlet. The magnitude of the voltage depends on the pulse rise time and the characteristics and cable length. These models are applied to perform computer simulations using MATLAB. The simulation program is very useful for the analysis of voltage and provides a convenient tool for a more reasonable design of the $\mathrm{dv} / \mathrm{dt}$ filters . The major networks $\mathrm{dv} /$ dt filters are investigated and the design equations are presented for each topology. Through simulation and analysis, an alternative design is suggested based on the comparison of the losses of the filter and the peak voltage of the motor terminals.Experimental results of the overvoltage and of the application of the filter are presented showing the validity of the RC simulation models [21]-[24].

However some of the industrial applications such as artificial lift systems in offshore oil operations, fan drives in underground mines which are using portable motors, the restrictions are such that the motor and PWM inverter must be placed in separate places. So long interconnect cables are often required between them. Contracted PWM pulses that are travel through long cables of power to the motor will behave as traveling waves on transmission lines, in which a voltage reflection phenomenon and possibly subsequent voltage reflection leading overvoltages in the motor terminals will occur. Indeed, the associated reflection occurs in and as a function of voltage when the inverter output of the pulse, and the length of the motor cables and surge impedances of the motor systems and cable. In this case, if improvement measures are not implemented, the drive would probably suffer from severe insulation damage leading ultimately to failure. The extent of this report is to study different improvement techniques for the industrial applications which are mentioned above. Detailed review of the passive filter at the terminals of the motor and drive, and the evaluation of the critical cable length evaluation is being done. This paper proposes that the aim to investigate the effect of transient overvoltages on ac induction motors when connected through a cable of arbitrary length to IGBT-PWM inverters and also the capacity of the high voltage phenomenon of the inverter fed induction motor. The problem and the importance of identifying the transients due to the peak overvoltages and estimate the appropriate precautions to be used by the cables is addressed.

\section{Matlab Model Of An Inverter Fed Induction Motor}

The computer simulations are based on MATLAB SIMULINK MODEL of the entire system. to analise the simulation programe, $230 \mathrm{~V}$ DC supply is used as the inverter input. Pulse width modulation inverter is used in 180 degree conduction mode. A $10 \mathrm{HP} 220 \mathrm{~V} 3$-phase induction motor is used. The simulation model is shown in fig. 1.In the simulation programe, the high frequency model fed inverter induction motor is designed using the above concept. In the model of the inverter, the technique of PWM is used and also IGBT is used as a switch. In this model different cabel per meter is connected between the inverter and the motor which is in the range of $3 \mathrm{HP}$, and a voltage pulse $200 \mathrm{~V}$ is applied to the motor through the cable.

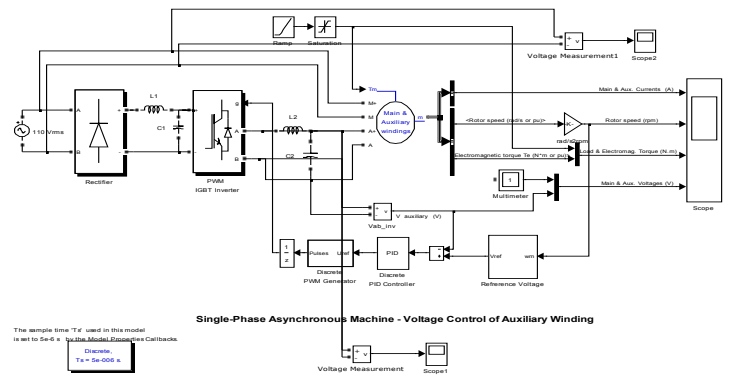

Figure-1. A simulation model of high frequency inverter fed induction motor to investigate the trasients.

The simulation results are carried out to monitor the over-voltage at the motor terminals. Fig. 2 shows the over-voltage in the conventional model of the machine. High $\mathrm{dv} / \mathrm{dt}$ spikes of the order of around $1000 \mathrm{~V}$ can be observed from the above simulation result. This leads to heavy stress on the motor insulation leading to partial discharge which in turn deteriorates insulation and thereby reduces the lifetime of the motor.

\subsection{High Frequency Modeling of the Cable}

For the power cable, it is well known that distributed-parameter representation provides more accurate results in the study of high-frequency transients than the lumped-parameter models. This model is shown in Fig.3. 


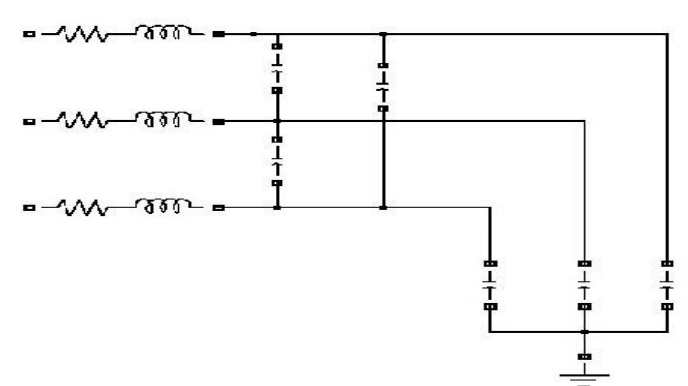

Figure 3. Distributed parameter model of the cable

The cable parameters per meter are:

$\mathrm{R}($ line resistance $=12.96 \mathrm{~m} \Omega / \mathrm{m}$

$\mathrm{L}($ line inductance $)=0.34 \mu \mathrm{H} / \mathrm{m}$

$\mathrm{Cg}$ (line-to-ground capacitance) $=181 \mathrm{pF} / \mathrm{m}$

$\mathrm{Cm}$ (line-to-line capacitance) $=32.5 \mathrm{pF} / \mathrm{m}$

\subsection{High frequency modeling of the induction motor}

It is not necessary to verify how voltage distributes inside the ac machine winding in order to calculate the over-voltage. It is important, rather, to know the value of the ac motor input impedance and how it varies as a function of frequency. This model is shown in Fig.4.

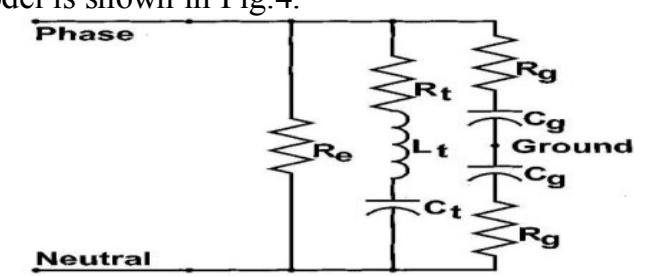

Figure.4 High Frequency Model of the Induction Motor

$\mathrm{Cg}=704 \mathrm{pF}, \mathrm{Rg}=23.2 \Omega, \mathrm{Rt}=0.086 \mathrm{k} \Omega, \quad \mathrm{Lt}=0.09 \mathrm{mH}, \mathrm{Ct}=70.4 \mathrm{pF}, \mathrm{Re}=1.4 \mathrm{k} \Omega$

$\mathrm{Cg}$ denotes the winding-to-ground capacitance. $\mathrm{Rg}$ represents the dissipative effects present in the motor frame resistance. The circuit formed by the parameters $\mathrm{Rt}, \mathrm{Ct}$ and $\mathrm{Lt}$ is the part of the network responsible to capture the second resonance in the frequency response, which is related to the winding turn-to-turn capacitance. Re accounts for the losses due to eddy currents present inside the magnetic core.

\section{Voltage Reflection Analysis}

On long cables, PWM pulses traveling between the inverter and the motor behave like traveling waves on transmission lines. Forward-traveling waves, or PWM pulses, travel from the inverter to the motor, while backward-traveling waves move toward the inverter due to voltage reflection. The reflection mechanism can be viewed as a mirror that produces a reflected wave $\mathrm{V}$ - which is a replica of $\mathrm{V}+$ that is "flipped around" such that all points on the $\mathrm{V}$ - waveform are the corresponding points of the $\mathrm{V}+$ waveform multiplied by the voltage reflection coefficient. The voltage reflection coefficient KL, at the motor terminals is determined by the surge impedance ratio at the junction point.

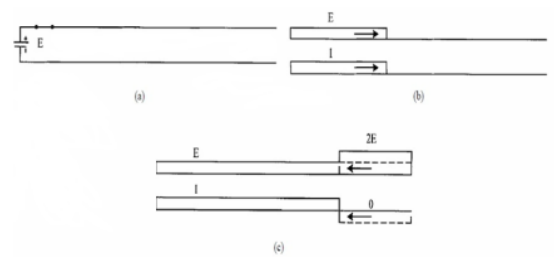

Figure 5. Voltage doubling due to reflection process

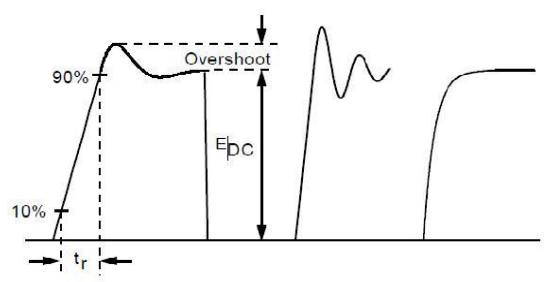

Figure 6.Pulses with various rise times 


\section{Analysis Of Overvoltages}

The simulation results show the over voltage at motor terminal for different gauges.

1. Graphically the variations in terminal voltage of motor for various stags of the inverter fed induction motors versus the time are represented in Figure-8 to Figure10. It shows the over voltage at motor terminal for different cable length the high voltage can be measured. Graphically the variations in terminal voltage of motor for various cable lengths versus with output time of the induction motor are represented in the same. It clearly shows that peak voltage value increases stability.
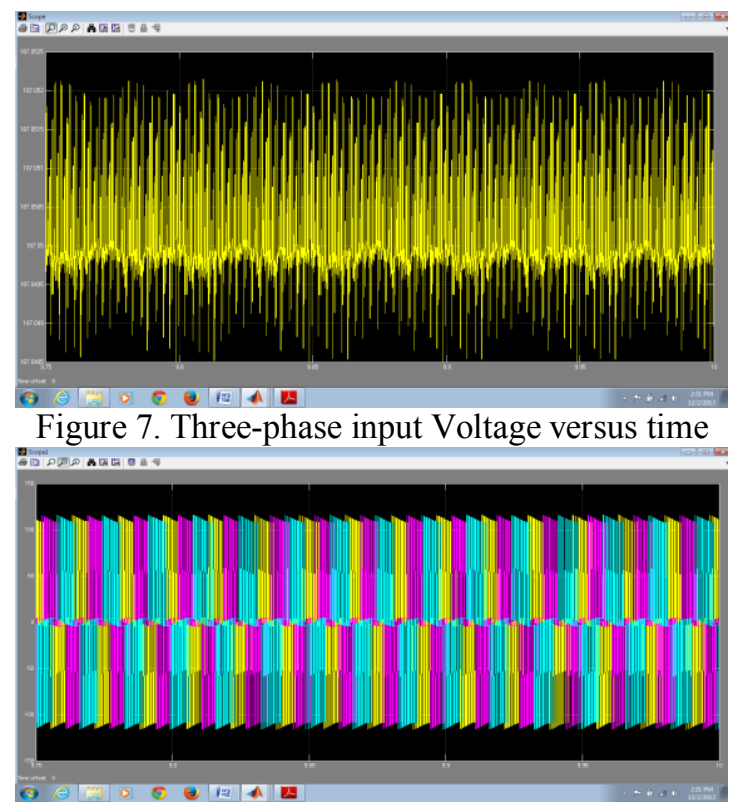

Figure 8. Three-phase inverter Voltage versus time

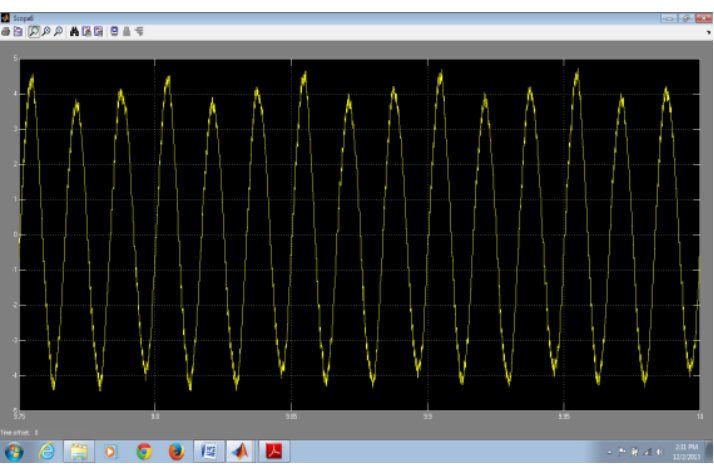

Figure 9. Three-phase Voltage for Induction motor versus time

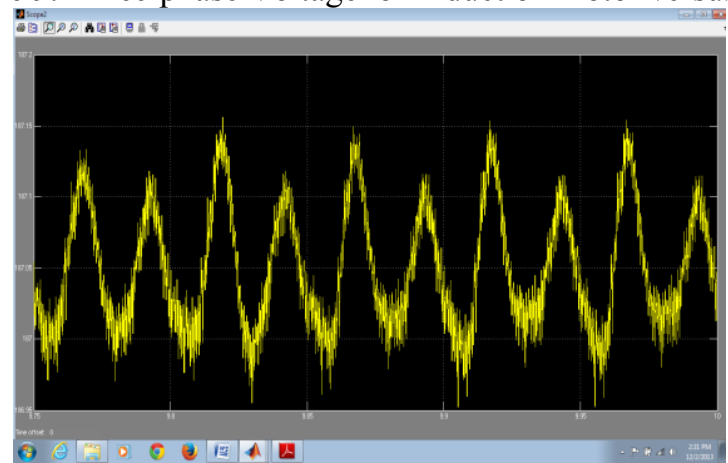

Figure 10. Three-phase Voltage before inverter versus time

4.1.Critical cable length: In some applications, long distances are forced between motor and control. This has an adverse effect because of increased power transistor switching frequencies and reflected voltage waveforms. Therefore it is essential to optimize the cable length used in such applications. We define a quantity called 
critical length for choosing the appropriate cable length. The critical cable length is the maximum cable length at which voltage amplification does not occur. It is the length at which the sum of the reflected and incident waves is equal to the peak value of the incident wave. If the propagation speed of the voltage wave is $S$ and the rise time of the PWM wave front is Tr, then the critical lead length is given by:

$\mathrm{L}_{\text {critical }}=\mathrm{S} \mathrm{X} \operatorname{Tr} / 2$

$\mathrm{S}=1 / \sqrt{\mathrm{LC}}(4.4)$

$=1 / \sqrt{ }(0.34$ X 10-6 X 181X 10-12)

$\mathrm{S}=127 \mathrm{~m} / \mu \mathrm{s}$

Typical rise time of IGBT $=0.1 \mu \mathrm{s}$

Lcritical $=6 \mathrm{~m}$

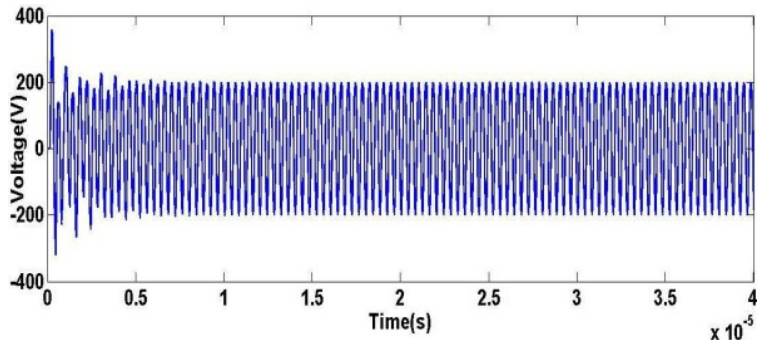

Figure .11. Voltage waveform at critical cable length $=200 \mathrm{~V}$

Fig. 8 shows the proposed per-phase high-frequency motor model that is used in the calculation of the overvoltage analysis. The suggested model is a lumped-parameter representation of the motor input impedance for which the calculated frequency response matches the experimental response. the dynamic model is partly responsible for capturing the low-frequency transients, while the remaining network is responsible to represent the high-frequency phenomena. Winding-to-ground capacitance and winding turn-to-turn capacitance plays the major role in the high-frequency phenomena [10], [11]. Their relation with the leakage inductance forms the dominant poles in the frequency response.

\section{Simulation And Experimental Analysis Of The Overvoltage}

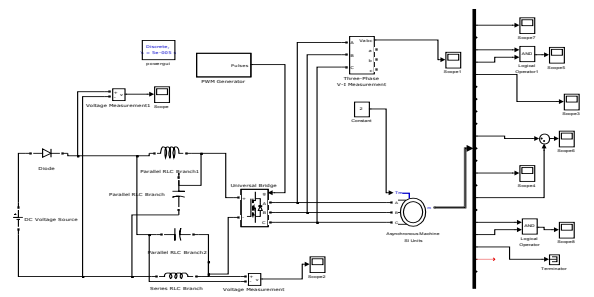

Figure.12.Simulation model of overvoltage inverter fed induction motor for various cable length

A flexible program was built in MATLAB that allows one to estimate the overvoltage phenomenon precisely for different cable lengths and for different voltage pulse rise times. These wave form are as shown in above figures. In the simulation program, one chooses the number of lumped sections as well as the simulation time step. The whole system can be simulated in a two-axes $(d-q)$ approach, which reduces the differential equations. The numerical integration is realized using Newton-Rahpson Method order 4 [4]. Simulation results were obtained for a system with a 3-HP motor and \#6 AWG driving cable with different lengths. Figs. 13-14 show the overvoltage waveforms for different power cable lengths. In each figure, the plots are the simulation realized in MATLAB using the above mentioned high-frequency models. The accuracy of the simulation models in predicting the overvoltage is readily evident from the plots. Additional simulation results are shown in Figures where the behavior of the line-to-line voltage at the machine terminals can be examined as a function of the voltage pulse rise times. It can be accomplished from these results that the proposed overvoltage simulation approach is a useful tool to predict, with reasonable accuracy, the magnitude of the overvoltage in the machine winding. 


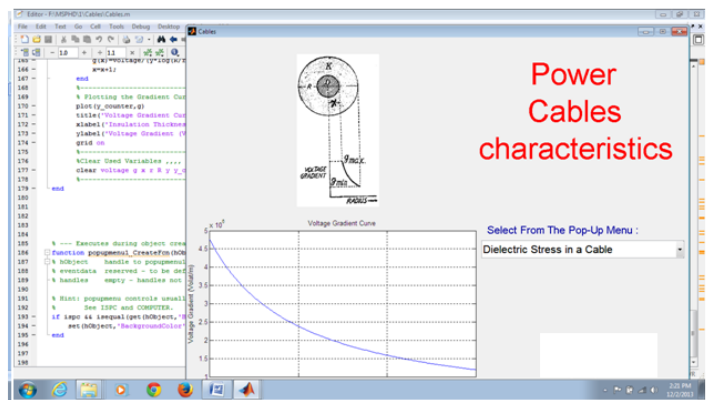

Figure.13.Relation Between Cable Insulation Resistance \& Length of The Cable

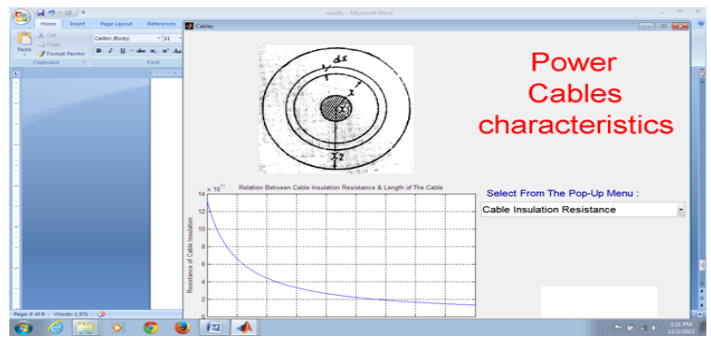

Figure.14.Relation Between Cable Insulation Resistance \& Length of The Cable

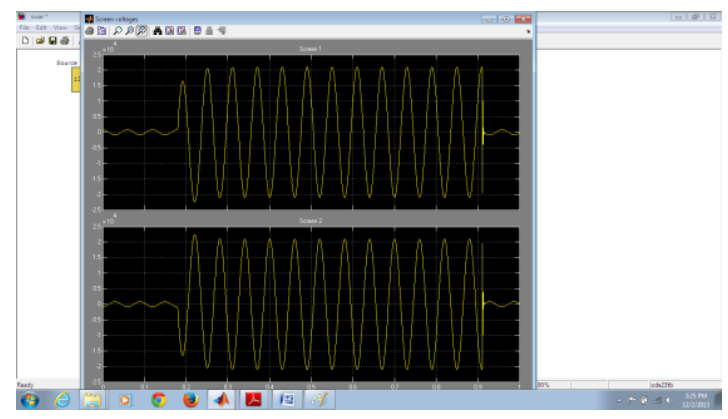

Figure. 15.The simulation result of Cable gauge $\# 20$

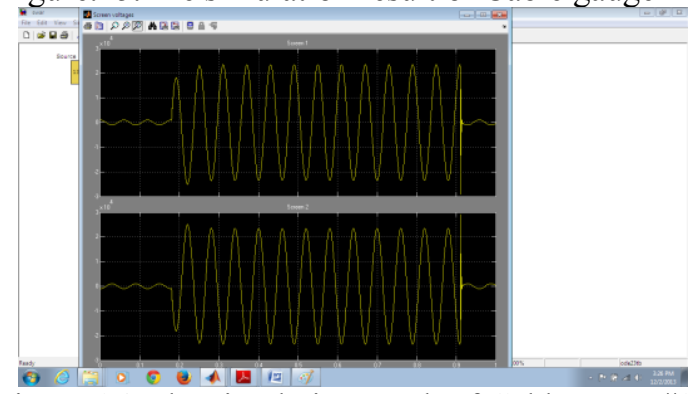

Figure.16. The simulation result of Cable gauge\#25

\section{Conclusions}

This paper deals with the analysis and improvement of over-voltages in IGBT based PWM fed Induction motor drives. Also this paper is based on a computer simulation program was used in the investigation of the overvoltage phenomena in long cable PWM fed induction motor drives. From the simulation it is concluded the following points to be considered:

- Impedance mismatch between surge impedance of the cable and motor causes voltage doubling at the motor terminals. High switching frequencies and long cable lengths cause the voltage to shoot-up beyond twice the peaksupply voltage.

- At critical cable length, no voltage amplification occurs. High frequency modeling of the cable and induction motor is required for accurate analysis.

- Optimization of cable-length between the inverter and motor will reduce the impedance mismatch and it is done based on critical cable length calculation.

The voltage pulse initiated at the inverter can be easily adjusted to better represent in the reality. The power cable is represented and explained here as a transmission line with lossy characteristics and modeled 
using several lumped parameter segments. This paper discussed the over-voltage phenomena in long cable PWM drives due to voltage reflection theory. The simulation analysis has been made with the effect of cable length and cable gauge alyzed. As the cable length increase the magnitude oon the overvoltage are anf over voltage increases.

\section{References}

[1] Persson E. 1992. Transient Effects in Application of PWM Inverters to Induction Motors. IEEE Transactions on IA. 28(5): 10951101 .

[2]. Basavaraja, B. and Sarma, D.V.S.S. (2006) "Application problem of PWM AC drives due to long cable length and high dv/dt", Vol.06,pp. 1-6.

[3]. Demmig, S. Andrews, J. and Klug, R.-D. (2011) "Control of subsea motors on multi-km cable lengths by variable frequency drives", Petroleum and Chemical Industry Conference Europe Conference Proceedings (PCIC EUROPE), Rome, Italy, pp. 1-10.

[4] H. Bonnett. 1996. Analysis of the impact of pulsewidth modulated inverter voltage waveforms on AC induction motors. IEEE Trans. Ind. Applicant. 32: 386-392, Mar/Apr.

[5] A.F. Morira, T. A.Lipo, G. Venkataramanan and S.Bernet. 2001. High Frequency Modelling for Cable and Induction Motor Overvoltage Studies in Long Cable Drives. IEEE Industrial Applications Society36th Annual Meeting Chicago, Illinois, USA, September 30-October 5 .

[6] Basava Raja and D.V.S.S. Siva Sarma. 2006. Modelling and Simulation of dv/dt filters for A.C Drives with fast switching Transients. Power India Conference. IEEE Publication on 10-12 April.

[7] G. Grandi, D. Casadei and A. Massarini. 1997. High frequency lumped-parameter Model for AC motor windings. In: Proc. EPE'97, Vol. 2, Trondheim, Norway. pp. 578-583.

[8] A. Boglietti and E. Carpaneto. 1999. Induction motor high frequency model. In: Conf. Rec. IEEE-IAS Annu. Meeting, Phoenix, AZ, Oct. 3-7. pp. 1551-1558. 